\title{
O PATÓgeno huMANO Paracoccidioides brasiliensis e a PARACOCCIDIOIDOMICOSE: UMA ABORDAGEM MÉDICA E MOLECULAR
}

\author{
THE HUMAN PATHOGEN Paracoccidioides brasiliensis AND \\ PARACOCCIDIOIDOMYCOSIS: A MEDICAL AND MOLECULAR \\ APPROACH
}

\author{
Rodrigo da Silva Santos ${ }^{1}$ \\ Patrícia de Sousa Lima \\ Leonardo Barcelos de Paula ${ }^{3}$ \\ Angela Adamski da Silva Reis ${ }^{4}$ \\ Mônica Santiago Barbosa ${ }^{5}$
}

1 - Biólogo. Departamento de Genética/Departamento de Bioquímica e Imunologia, Faculdade de Medicina de Ribeirão Preto, Universidade de São Paulo.

2 - Bióloga. Departamento de Patologia Molecular, Faculdade de Medicina, Universidade de Brasília

3 - Biólogo. Departamento de Genética, Faculdade de Medicina de Ribeirão Preto, Universidade de São Paulo.

4 - Biomédica. Professora Adjunta do Departamento de Bioquímica e Biologia Molecular, Instituto de Ciências Biológicas, Universidade Federal de Goiás.

5 - Biomédica. Professora Adjunta e Orientadora, Departamento de Ciências Biológicas e da Saúde, Universidade Federal de Goiás, Campus Jataí-GO.

Email: rdssantos@gmail.com (Santos, RS)

RESUMO: Doenças infecciosas são decorrentes de uma relação intima entre o patógeno e seu hospedeiro e o conhecimento desta complexa interação é essencial para se avançar no conhecimento dos mecanismos de estabelecimento das infecções. O patógeno Paracoccidioides brasiliensis, é o agente etiológico da Paracoccidioidomicose (PCM), uma micose humana sistêmica que afeta principalmente a população rural das Américas Latinas e do Sul, sendo no Brasil registrados $80 \%$ dos casos da doença. A PCM afeta principalmente indivíduos do sexo masculino entre 30 e 60 anos que desempenham atividades agrícolas. A doença em geral apresenta evolução crônica, caráter recidivante e pode deixar sequelas anatômicas e funcionais. No Brasil, a doença causa aproximadamente 200 mortes por ano, sendo o país considerado o maior centro endêmico desta micose. Sendo assim, é grande a quantidade de doentes que necessitam de assistência médica de longo prazo nas regiões de maior endemicidade, tornando a moléstia, pela sua prevalência, um importante problema de saúde pública.

Palavras-Chave: Doenças Infecciosas, Paracoccidioides brasiliensis, Paracoccidioidomicose, Estudos Moleculares, Fatores de Virulência.

\begin{abstract}
Infectious diseases are the result of an intimate relationship between the pathogen and its host and the knowledge of this complex interaction is key to progress in understanding the mechanisms of establishment of infection. The pathogen Paracoccidioides brasiliensis is the etiological agent of Paracoccidioidomycosis (PCM), a human systemic mycosis that affects mainly the rural population of Latin America and South America, in Brazil and $80 \%$ of registered cases. The PCM mainly affects males between 30 and 60 years who perform agricultural activities. The disease usually presents chronic disease, and recurrent character may anatomic and functional sequelae. In Brazil,
\end{abstract}


the disease causes about 200 deaths per year, the country being considered the largest center of this endemic mycosis. So great is the number of patients requiring long-term care in areas of highest endemicity, making the disease, because of its prevalence, a major public health problem.

Keywords: Infectious Diseases, Paracoccidioides brasiliensis, Paracoccidioidomycosis, Molecular Studies, Virulence Factors.

\section{Introdução}

Os fungos são caracterizados por serem agentes comuns em todo ecossistema, onde são organismos de vida livre e saprobiótica, desempenhando um papel fundamental ao ser um dos constituintes da base de cadeias e teias alimentares, fazendo a decomposição da matéria orgânica. Estes microrganismos possuem um importante papel na saúde dos animais, causando desde micoses classificadas como cutâneas até micoses sistêmicas (Murray et al. 2004; Schaechter et al. 2002).

Embora existam aproximadamente 100.000 espécies fúngicas, apenas um pequeno grupo causa micose sistêmica humana (San-Blas \& Niño-Vega, 2004). Os fungos dimórficos são responsáveis pela maior parte das infecções fúngicas sistêmicas de humanos e outros mamíferos. O processo da doença é marcado pela conversão do fungo de uma forma infecciosa não patogênica, presente no ambiente, para uma forma patogênica, morfologicamente distinta, no tecido. Conídios ou fragmentos dispersos no solo é a forma infecciosa primária desses agentes, atingindo o hospedeiro pela via respiratória e após a inalação, rapidamente convertem-se à forma leveduriforme. A infecção pode resultar desde uma micose pulmonar contida ou assintomática até doença fatal (Rappleye \& Goldman, 2006).

Os organismos causadores de micoses sistêmicas humanas são inerentemente virulentos, como é o caso do fungo Paracoccidioides brasiliensis, patógeno humano agente etiológico da Paracoccidioidomicose (PCM) (Lutz, 1908). A forma infectiva, miceliana é encontrada em condições saprobióticas no ambiente, ou quando cultivada em temperaturas inferiores a $28^{\circ} \mathrm{C}$ (Brumer et al., 1993). A forma miceliana do fungo é caracterizada por micélios septados com conídios terminais ou intercalares. A forma leveduriforme parasitária se desenvolve nos tecidos infectados ou quando cultivada in vitro a $36^{\circ} \mathrm{C}$, sendo caracterizada por apresentar brotamentos múltiplos originados por evaginações da célula-mãe, onde uma célula central grande é circundada por células periféricas menores, apresentando um aspecto de roda de leme de navio, o que caracteriza a presença de $P$. brasiliensis em materiais biológicos (Queiroz-Telles, 1994; RestrepoMoreno, 2003). 


\section{A Biologia e os aspectos moleculares} do patógeno Paracoccidioides brasiliensis

P. brasiliensis é um fungo caracterizado por apresentar dimorfismo térmico, aspecto importante como mecanismo de virulência e de patogenicidade. A transição entre as morfologias de micélio e levedura constitui-se em uma etapa essencial para o sucesso no estabelecimento da infecção e para a fase inicial da interação do fungo com o hospedeiro (San-Blas et al., 1987). Um dos estímulos ambientais mais notórios no dimorfismo do $P$. brasiliensis é a temperatura. $\mathrm{O}$ fungo se apresenta como micélio a $22^{\circ} \mathrm{C}$ $25^{\circ} \mathrm{C}$ e como levedura a $35^{\circ} \mathrm{C}-37^{\circ} \mathrm{C}$ ( Brumer et al., 1993). Além da temperatura, fatores nutricionais também podem interferir no processo dimórfico do patógeno. A adição de soro fetal bovino tanto à meio de cultura complexo quanto à meio quimicamente definido permitiu preservar a expressão fenotípica de leveduras, a $25^{\circ} \mathrm{C}$ (Villar et al., 1988).

Um dos aspectos da relação entre o parasita e o hospedeiro é o efeito de hormônios no dimorfismo do fungo. A alta incidência de PCM em adultos masculinos sugere que fatores hormonais possam desempenhar papel na patogênese da doença (Sano et al., 1999). Estudos mostraram que o hormônio 17- $\beta$-estradiol é capaz de inibir a transição de micélio para levedura de maneira dose-dependente, in vitro (Restrepo, 1985), e in vivo (Sano et al., 1999). Aristizabal et al., (2002), observaram, in vivo, a participação do hormônio feminino na resistência de fêmeas de rato ao desenvolvimento inicial da PCM. Análises transcricionais (Felipe et al., 2005) descreveram um gene preferencialmente expresso na fase leveduriforme de $P$. brasiliensis que potencialmente codifica uma proteína de ligação ao 17- $\beta$-estradiol, previamente caracterizada (Loose et al., 1983). A EBP (“Estradiol Binding Protein”) possui interação seletiva a estrogênios ligando-se ao estradiol no citoplasma (Clemons et al., 1989; Loose et al., 1983). Acredita-se que a interação do hormônio 17$\beta$-estradiol com a EBP citoplasmática iniba a transição de micélio para levedura, explicando a baixa incidência da PCM em mulheres.

O perfil transcricional de $P$. brasiliensis durante a diferenciação morfológica de micélio para levedura foi avaliado por Bastos et al. (2007). Vários transcritos potencialmente relacionados com a síntese de membrana e parede celulares mostraram-se aumentados durante a diferenciação celular de micélio para levedura, após 22 horas de indução da transição, sugerindo que $P$. brasiliensis priorize o remodelamento da membrana e de parede celulares nos estágios iniciais da morfogênese. Neste estudo, genes envolvidos na via de assimilação do enxofre como a sulfito redutase, mostraram-se super 
expressos durante a transição, sugerindo o envolvimento do metabolismo do enxofre durante o processo de diferenciação em $P$. brasiliensis. Durante a transição dimórfica também foi verificada a presença de enzimas que participam do ciclo do glioxalato, como isocitrato liase, malato desidrogenase, citrato sintase e aconitase. A presença destes transcritos durante a diferenciação indica que esta via é funcional durante esse processo. Também foram identificados genes envolvidos em vias de transdução de sinal tais como MAPK, serina/treonina quinase e histidina quinase, sugerindo que a transição morfológica em P. brasiliensis é mediada por vias de transdução de sinal que controlam a adaptação ao ambiente para a sobrevivência do fungo dentro do hospedeiro.

Estudos filogenéticos moleculares em fungos vêm sendo focados particularmente no RNA ribossomal (rRNA) e no DNA ribossomal (rDNA), sendo importantes ferramentas na distinção de espécies (James et al., 1996). A comparação filogenética de dermatófitos e de fungos dimórficos baseados na subunidade ribossomal $18 \mathrm{~S}$, classificou $P$. brasiliensis, mais precisamente, como pertencente ao filo Ascomycota, à ordem Onygenales e à família Onygenaceae, juntamente com Blastomyces dermattidis e Histoplasma capsulatum (Leclerc et al., 1994; Bialek et al., 2000). Atualmente com base em estudos de filogenia molecular, P. brasiliensis é descrito como pertencente ao reino Fungi, filo Ascomycota, subdivisão Euascomycotina, classe Plectomyceto, subclasse Euascomycetidae, ordem Onygenales, família Onygenaceae, subfamília Onygenaceae Anamórficos, gênero Paracoccidioides, espécie Paracoccidioides brasiliensis (SanBlas et al., 2002). Três espécies filogenéticas de $P$. brasiliensis S1, PS2 e PS3 foram identificados, através de dados de polimorfismo genético. A espécie filogenética PS3 encontra-se restrita à Colômbia, enquanto $\mathrm{S} 1$, que tem como representante o $\mathrm{Pb} 18$, que distribui-se no Brasil, Argentina, Paraguai, Peru e Venezuela. Isolados da espécie PS2 foram também encontrados no Brasil e Venezuela. Todas as três espécies foram capazes de induzir a doença em hospedeiros humanos e animais; entretanto uma menor virulência tem sido verificada nas espécies PS2 (Matute et al., 2006).

Ainda com o objetivo de se estabelecer relações filogenéticas entre isolados de $P$. brasiliensis, análises foram realizadas com base na comparação de sequiências de regiões codantes, não codantes e seqüências espaçadoras internas - ITS (internally transcribed sequence) de 21 isolados. Todos os isolados analisados se agruparam nos três grupos filogenéticos anteriormente descritos. $\mathrm{O}$ isolado $\mathrm{Pb} 01$, apresentou-se filogeneticamente distinto dos outros isolados analisados, agrupando-se apenas com o isolado IFM 54648, obtido de um paciente do estado do Paraná/Brasil. Os 
resultados obtidos sugerem a possibilidade de ocorrência de mais de três espécies filogenéticas em $P$. brasiliensis. Os isolados Pb01 e IFM 54648 apresentam-se geneticamente separados dos outros isolados por um longo período de tempo, sugerindo que os mesmos possam constituir uma nova espécie do gênero Paracoccidioides (Carrero et al., 2008).

\section{O nicho ecológico do $P$. brasiliensis} ainda não está completamente esclarecido. Entretanto algumas hipóteses são descritas. Alguns estudos sugerem que o fungo viva saprobioticamente na natureza, pois o mesmo já foi isolado de solo, água e plantas (Restrepo et al., 2001). Devido à presença de poucos isolados de $P$. brasiliensis no solo, acredita-se que este ambiente não seja o habitat permanente do patógeno, sugerindo que o fungo resida por tempo variável nestes locais (Conti-Diaz, 2007). Theodoro e colaboradores (2005) sugeriram que alguns tipos de solos devem ser mais favoráveis à produção de conídios, um aspecto importante por aumentar a eficiência de sobrevivência do microrganismo no meio ambiente, bem como a capacidade de infectar humanos. Corroborando essa hipótese, Franco e colaboradores (2000) demonstraram que diferentes condições do solo alteram a capacidade de crescimento da forma miceliana e a produção de conídeos por $P$. brasiliensis. Experimentos realizados por Terçarioli e colaboradores (2007) envolvendo o cultivo de vários isolados de $P$. brasiliensis em diferentes tipos de solo demonstraram que este fungo apresenta a capacidade de crescimento em solos arenosos e argilosos, com alta umidade, sendo que em alguns isolados, pode-se observar a produção de conídios.

Presume-se que o fungo $P$. brasiliensis ocorra normalmente em ambientes úmidos, próximos a rios, onde possa ser protegido por representantes de espécies aquáticas heterotérmicas como moluscos, anfíbios, peixes e artrópodes. Estes organismos estariam fornecendo ao parasita, nutrientes, umidade, competição biológica limitada e temperatura apropriada para a sobrevivência do micélio no meio ambiente (Conti-Diaz, 2007). A infecção natural do fungo em alguns animais silvestres como tatus (Dasypus novemcinctus, Dasypus septemcinctus e Cabassous centralis) e animais domésticos, como cachorros (Canis familiares), também tem sido observada; entretanto estes organismos devem ser considerados hospedeiros acidentais e não reservas naturais do fungo, pois os mesmos podem ser acometidos com a doença (ContiDiaz, 2007).

Estudos de detecção molecular de $P$. brasiliensis realizados por Richini-Pereira e colaboradores (2007) em animais selvagens mortos encontrados em estradas e rodovias, foram realizados, por meio da técnica de Nested-PCR (reação em cadeia da 
polimerase) com oligonucleotídeos ITS específicos para $P$. brasiliensis. Foi detectada a presença do fungo em tatu (Dasypus sp.), porco-da-índia (Cavia aperea), porco espinho (Sphigurrus spinosus), guaxinim (Procyon cancrivorus) e furão (Gallictis vittata). Os dados revelam que a infecção em animais silvestres de áreas endêmicas é mais alta do que era proposto inicialmente e demonstram a importância do uso de animais mortos em estradas no estudo eco-epidemiológico do fungo.

A organização genômica do $P$. brasiliensis tem sido investigada. Utilizandose a técnica de gel em eletroforese de pulso alternado (PFGE) foi possível identificar-se 4 ou 5 cromossomos com 2-10 Mb tanto de fungos isolados do meio ambiente, quanto de isolados clínicos. Desta maneira, estimou-se que $P$. brasiliensis apresentasse um genoma variando entre 23-31 Mb (Feitosa et al., 2003). Estudos com 10 isolados de $P$. brasiliensis, por citometria de fluxo, incluindo representantes das três espécies filogenéticas recentemente identificadas, demonstraram que o fungo apresentava um genoma variando de 26,3 a 35,5 Mb por célula de leveduras uninucleadas. O genoma dos conídios apresentou um tamanho de 30,2 a 30,9 Mb, não havendo, portanto, nenhuma diferença significativa com a forma de levedura (Almeida et al., 2007).

Os genomas estruturais de três isolados de $P$. brasiliensis (Pb01, Pb03 e
Pb18) foram completados através do projeto denominado "Genômica Comparativa de Coccidioides e outros Fungos Dimórficos", realizado pelo Broad Institute of MIT and Havard, confirmando a presença de 5 cromossomos em cada isolado. O genoma do isolado Pb01 é composto de $32,94 \mathrm{Mb}$, com um total de 9.132 genes. Este isolado apresenta o genoma maior tanto em número de bases quanto em quantidade de genes comparado aos outros dois isolados analisados, que apresentaram genomas do tamanho de 29,06 e 29,95 Mb, com número de genes de 7.875 e 8.741 (dados dos isolados $P b 03$ e $P b 18$, respectivamente). Os resultados obtidos além de auxiliar na compreensão das diferenças existentes entre os isolados proporcionarão a caracterização de genes e suas regiões promotoras, e o desenvolvimento de novas ferramentas biomoleculares e genéticas para a elucidação de aspectos da biologia de $P$. brasiliensis, que até então são desconhecidos.

\section{A patologia Paracoccidioidomicose (PCM)}

A Paracoccidioidomicose (PCM) é uma micose humana sistêmica granulomatosa, enfermidade de alta prevalência e morbidade que acomete parcelas da população com menor capacidade de acesso a serviços de saúde, em áreas limitadas somente a alguns países da América Latina. $\mathrm{O}$ fungo $P$. brasiliensis infecta hospedeiros humanos 
usualmente através das vias respiratórias, por inalação de propágulos do micélio e artroconídeos (Bagagli et al., 2006). A primeira interação parasita-hospedeiro ocorre nos alvéolos pulmonares; a partir dos pulmões, o fungo pode disseminar-se por vias hematogênica ou linfática acometendo outros órgãos e sistemas como fígado, baço, ossos e sistema nervoso central (Camargo \& Franco, 2000; San-Blas, 1993; Valera et al., 2008).

A PCM apresenta duas formas clínicas principais: forma aguda ou subaguda (juvenil) e forma crônica (adulta). A forma juvenil atinge crianças de ambos os sexos, tem evolução mais rápida e é mais severa levando a taxas de mortalidade significantes, afetando principalmente o sistema retículo endotelial. A forma adulta, por sua vez, é altamente prevalente entre adultos do sexo masculino, tem progressão lenta e compromete primeiramente os pulmões, podendo a partir daí disseminar-se para outros órgãos e tecidos formando lesões secundárias (Franco, 1987). $\mathrm{O}$ progresso da patologia e a diversidade das formas clínicas dependem dos fatores imunológicos do hospedeiro (Franco, 1987) e dos diferentes níveis de virulência dos diversos tipos de isolados do fungo (PanuntoCastelo et al., 2003; San-Blas \& Nino-Vega, 2001)

A distribuição geográfica da PCM apresenta-se restrita à países da América Latina, onde um grande número de habitantes é acometido (Brummer et al., 1993; Lacaz et al., 1991). O Brasil é considerado o maior centro endêmico desta micose, pois $80 \%$ dos casos da doença descritos na literatura foram diagnosticados no país. As regiões Sul, Sudeste e Centro-Oeste apresentam o maior número de registros (Paniago et al., 2003). A moléstia é responsável por 200 mortes ao ano aproximadamente, representando um grande problema de saúde pública. De acordo com os registros do Ministério da Saúde, de 1980 a 1995 ocorreram no Brasil 3.181 casos de óbito, o que totaliza uma taxa de mortalidade por PCM de 1,45 casos por milhão de habitantes. Esses dados apontam a PCM como a oitava causa de mortalidade por doença infecciosa. Desta forma, a doença representa um importante problema de saúde pública devido ao seu alto potencial incapacitante e à quantidade de mortes prematuras que provoca (Shikanai-Yasuda et al., 2006).

A real prevalência e incidência não podem ser calculadas, pois a PCM não é uma doença notificável e o local e as condições exatas em que o fungo ocorre na natureza ainda não estão bem determinados. Nos países onde a doença é endêmica, os casos não são distribuídos homogeneamente ao longo do território, mas tendem a se concentrar em torno das florestas úmidas (Restrepo, 1985).

Alguns casos autóctones já foram diagnosticados na Europa, nos Estados Unidos da América e na Ásia (Ajello \& Polonelli, 1985). Estes relatos possibilitaram a determinação de um período assintomático da 
PCM, o qual é em média 15,3 anos, que ocorre após o contato do paciente com a área endêmica até a manifestação da doença (Brummer et al., 1993). O longo período de latência, característico da PCM, dificulta o processo de determinação precisa do sítio onde a infecção ocorreu (Borelli, 1972).

Nas áreas endêmicas da doença a incidência estimada é de, aproximadamente, 1 a 3 casos clínicos para cada 100.000 habitantes por ano (Coutinho et al., 2002). A PCM atinge preferencialmente trabalhadores rurais do sexo masculino, entre 30 a 50 anos de idade (Svidzinski et al., 1999; Villa et al., 2000). O trabalho com solo e plantações em área rural é fator ocupacional predisponente para a aquisição da PCM (Franco, 1987). A incidência da doença até à puberdade é a mesma em ambos os sexos, porém na fase adulta, mais de $90 \%$ dos pacientes são do sexo masculino (Martinez, 1997). Acredita-se que esse fato seja explicado pela ação protetora que os hormônios estrógenos conferem ao sexo feminino (Sano et al., 1999), e pela ausência ou menor contato das mulheres com as fontes de infecção (Shikanai-Yasuda et al., 2006).

\section{O Diagnóstico e o Tratamento da PCM}

O diagnóstico comprobatório da PCM, assim como em outros processos infecciosos, se dá através de técnicas diretas de diagnóstico, demonstrando e reconhecendo o agente etiológico em preparados histológicos, exame a fresco ou em cultivo, porém já é comprovado que as metodologias indiretas nos permitem um maior grau de confiabilidade e certeza.

Os testes sorológicos constituem-se nas mais importantes dessas técnicas auxiliares, além de apresentar a função de acompanhamento durante e pós-tratamento. Das técnicas sorológicas rotineiramente utilizadas no diagnóstico a PCM, a imunodifusão (ID) ainda persiste como a mais importante, principalmente devido à simplicidade do teste, a ausência do uso de equipamentos de alto custo, a sensibilidade maior que $80 \%$ e a especificidade maior que $90 \%$, bem como pela fácil padronização (Shikanai-Yasuda et al., 2006). Valle et al. (2001), utilizando como substrato antigênico um filtrado de cultura, da fase leveduriforme, concentrada e dialisada de um "pool" de cepas de $P$. brasiliensis, obteve 90,2\% de sensibilidade diagnóstica com ID no total de 245 pacientes em pré-tratamento. Outras técnicas sorológicas mais elaboradas têm sido utilizadas somente em centros de referência e/ou de pesquisa, tais como a de contraimunoeletroforese (CIE), enzyme linked immunosorbent assay (ELISA) e Immunoblotting, consideradas em ordem crescente de sensibilidade.

Inicialmente foram apontados alguns antígenos imunodominantes para $P$. brasiliensis, apresentando massas moleculares 
de 70, 52, 43 e 20-21kDa, sendo destacada a glicoproteína de $43 \mathrm{kDa}$ reconhecida por $100 \%$ dos soros de pacientes naquele estudo (Camargo et al., 1989). Brito (1996), demonstrou o perfil antigênico do isolado Pb01 (ATCC-MYA-826) de ambas as formas de $P$. brasiliensis, usando soros de 50 diferentes pacientes, enumerando 21 proteínas como antígenos imunodominantes, as quais foram reconhecidas por mais de $50 \%$ dos soros testados, sendo que nenhuma havia reagido com todos eles. As proteínas com 61, 70 e $79 \mathrm{kDa}$, expressas em ambas as formas, foram reconhecidas por mais de $70 \%$ dos soros testados, sendo que a espécie antigênica de $29 \mathrm{kDa}$ foi preferencialmente expressa em leveduras e as espécies de 33, 47, 57, 63 e $84 \mathrm{kDa}$ foram expressas preferencialmente em micélio.

Fonseca et al. (2001), através de estudos de imunoproteômica, caracterizaram seqüências parciais de aminoácidos dos antígenos catalase, frutose-1-6-bifosfato aldolase, malato desidrogenase, triose fosfato isomerase e gliceraldeído-3-fosfato desidrogenase, todos preferencialmente expressos na forma leveduriforme de $P$. brasiliensis. Os genes correlatos foram posteriormente caracterizados e, como previsto, apresentaram expressão diferencial durante a transição dimórfica do fungo (Moreira et al., 2004; Pereira et al., 2004; Barbosa et al., 2004; Carneiro et al., 2005). Além disso, os genes codificantes das proteínas HSP70 (Silva et al., 1999), HSP60 (Salem-Izacc et al., 2001), ClpB (Jesuino et al., 2002), manosiltransferase (Costa et al., 2002), apresentam baixos níveis de expressão na forma miceliana, quando comparados com a forma de levedura de $P$. brasiliensis, sugerindo que estas proteínas sejam necessárias para sobrevida do fungo nas condições térmicas do hospedeiro e que possam desempenhar papel na morfogênese de $P$. brasiliensis.

Panunto-Castelo et al. (2003) trabalhando exclusivamente com exoantígenos de cinco diferentes isolados de $P$. brasiliensis, apontaram três proteínas mais reconhecidas por soros de quarenta pacientes com PCM ativa: as de 43kDa (97\%), 160-kDa (78\%) e 70-kDa (60\%). Atualmente, o diagnóstico molecular realizado através de técnicas biomoleculares, tais como a reação em cadeia da polimerase em tempo real, têmse demonstrado uma fonte potencial de sensibilidade e especificidade, fornecendo na maioria dos casos uma resposta rápida.

Para o tratamento da PCM, os clínicos dispõem de um variado arsenal de fármacos clássicos e variados (Shikanai-Yasuda et al., 2006). Embora P. brasiliensis tenha se mostrado sensível à maioria dos fármacos antifúngicos, o tratamento medicamentoso persiste como desafio não totalmente resolvido, assim como para diversas outras infecções fúngicas. 
$\mathrm{O}$ fármaco anfotericina $\mathrm{B}$ foi $\mathrm{O}$ primeiro tratamento administrado para muitos pacientes com micoses profundas, sendo reservada para os casos graves da PCM (Lacaz \& Sampaio, 1958). O fármaco é nefrotóxico e apresenta outros inúmeros efeitos colaterais, requerendo longo período de hospitalização para a sua administração. É utilizado por via endovenosa e atua mediante ligação ao ergosterol da membrana plasmática da célula fúngica, alterando a sua permeabilidade. Jesuíno (1995) estudou o efeito da anfotericina B sobre o crescimento celular in vitro do isolado $P b 01$ de $P$. brasilensis, e verificou inibição numa relação dose-dependente bem como a reversão da inibição com a retirada do fármaco.

Os derivados azólicos atuam por inibição da síntese do ergosterol da membrana plasmática da célula fúngica e três representantes dessa classe têm sido utilizados com eficácia no tratamento da PCM: cetoconazol, itraconazol e fluconazol, sendo o fluconazol em altas doses, o fármaco mais eficiente para o tratamento da neuroparacoccidioidomicose (Marques, 2003).

Atualmente novos fármacos antifúngicos têm sido desenvolvidos, porém não apresentaram respostas significativas para o tratamento da PCM. Pode-se citar como exemplo a família das equinocandinas, das quais a caspofungina que apresenta seu mecanismo de ação baseado na inibição da síntese da $\beta-1,3$ glucana da parede fúngica, não foi capaz de inibir o crescimento in vitro de $P$. brasiliensis, embora eficiente para o tratamento de outras infecções fúngicas, como a candidíase e a aspergilose (Queirós-Telles, 2002). Portanto vale ressaltar, que novas pesquisas científicas em busca de alvos para drogas altamente específicas devem continuar, de forma a sugerir novas abordagens terapêuticas.

\section{Referências}

AJELLO, L. \& POLONELLI, L. (1985). Imported paracoccidioidomycosis: a public health problem in non-endemic areas. Eur J Epidemiol 1(3): 160-5. 1985.

ALMEIDA, A. J., CARMONA, J. A., CUNHA, C., CARVALHO, A., RAPPLEYE, C. A., GOLDMAN, W. E., HOOYKAAS, P. J., LEAO, C., LUDOVICO, P. AND RODRIGUES, F. Towards a molecular genetic system for the pathogenic fungus Paracoccidioides brasiliensis. Fungal Genet Biol 44(12): 1387-98, 2007.

ALMEIDA, A. J., MATUTE, D. R., CARMONA, J. A., MARTINS, M., TORRES, I., MCEWEN, J. G., RESTREPO, A., LEAO, C., LUDOVICO, P. AND RODRIGUES, F. Genome size and ploidy of Paracoccidioides brasiliensis reveals a haploid DNA content: flow cytometry and GP43 sequence analysis. Fungal Genet Biol 44(1): 25-31, 2007.

ARISTIZABAL, BH, CLEMONS, KV, COCK, AM, RESTREPO, A AND STEVENS, DA. Experimental Paracoccidioides brasiliensis infection in mice: influence of the hormonal status of the host on tissue responses. Med Mycol 40(2): 169-78, 2002. 
BAGAGLI, E., BOSCO, S. M., THEODORO, R. C. AND FRANCO, M. Phylogenetic and evolutionary aspects of Paracoccidioides brasiliensis reveal a long coexistence with animal hosts that explain several biological features of the pathogen. Infect Genet Evol 6(5): 344-51, 2006.

BARBOSA, MS, CUNHA PASSOS, DA. FELIPE MS, JESUINO RS, PEREIRA M, SOARES C.M.A. The glyceraldehyde-3phosphate dehydrogenase homologue is differentially regulated in phases of Paracoccidioides brasiliensis: molecular and phylogenetic analysis. Fungal Genet. Biol. v. 41, p.667-675. 2004.

BASTOS, K. P., BAILAO, A. M., BORGES, C. L., FARIA, F. P., FELIPE, M. S., SILVA, M. G., MARTINS, W. S., FIUZA, R. B., PEREIRA, M. AND SOARES, C. M. The transcriptome analysis of early morphogenesis in Paracoccidioides brasiliensis mycelium reveals novel and induced genes potentially associated to the dimorphic process. BMC Microbiol 7: 29, 2007.

BIALEK, R., IBRICEVIC, A., AEPINUS, C., NAJVAR, L. K., FOTHERGILL, A. W., KNOBLOCH, J. AND GRAYBILL, J. R. Detection of Paracoccidioides brasiliensis in tissue samples by a nested PCR assay. J Clin

Microbiol 38(8): 2940-2. 2000.

BORELLI, D. Some ecological aspects of paracoccidioidomycosis.

Paracoccidioidomycosis. Medellin, Pan

Amer Hlth Org Scient Publ: 59-64, 1972.

BRITO WA. Identificação e caracterização de antígenos do fungo Paracoccidioides brasiliensis. 1996. 102f. Dissertação

(Mestrado em Biologia - Área de

Concentração: Bioquímica e Biologia

Molecular) - Instituto de Ciências Biológicas, Universidade Federal de Goiás, Goiânia, 1996.

BRUMMER E, CASTANEDA E, RESTREPO A. Paracoccidioidomycosis: an update. Clin Microbiol Rev. . 6:89-117, 1993.

CAMARGO ZP, UNTERKIRCHER C, TRAVASSOS LR. Identification of antigenic polypeptides of Paracoccidioides brasiliensis by immunoblotting. J Med Vet Mycol. 27: 407-412, 1989.

CAMARGO, Z. P. \& FRANCO, M. F. Current Knowledge on Pathogenesis and immunodiagnosis of paracoccidioidomycosis. Rev Iberoam Micol 17: 41-48, 2000.

CARNEIRO LC, FARIA FP, FELIPE MS, PEREIRA M, SOARES CMA.

Paracoccidioides brasiliensis presents two different cDNAs encoding homologues of the fructose 1,6-biphosphate aldolase: protein isolation, cloning of the cDNAs and genes, structural, phylogenetic, and expression analysis. Fungal Genet Biol. 2005. 42(1):5160

CARRERO, L. L., NINO-VEGA, G., TEIXEIRA, M. M., CARVALHO, M. J., SOARES, C. M., PEREIRA, M., JESUINO, R. S., MCEWEN, J. G., MENDOZA, L., TAYLOR, J. W., FELIPE, M. S. AND SANBLAS, G. New Paracoccidioides brasiliensis isolate reveals unexpected genomic variability in this human pathogen. Fungal Genet Biol, 45(5): 605-12, 2008.

CLEMONS, K. V., FELDMAN, D. AND STEVENS, D. A. Influence of oestradiol on protein expression and methionine utilization during morphogenesis of Paracoccidioides brasiliensis. J. Gen Microbiol 135(6): $1607-$ 17, 1989.

CONTI-DIAZ, I. A. On the unknown ecological niche of Paracoccidioides brasiliensis: our hypothesis of 1989: present status and perspectives. Rev Inst Med Trop São Paulo 49(2): 131-4, 2007.

CORREDOR, G. G., PERALTA, L. A., CASTANO, J. H., ZULUAGA, J. S., HENAO, B., ARANGO, M., TABARES, A. M., MATUTE, D. R., MCEWEN, J. G. AND 
RESTREPO, A. The naked-tailed armadillo Cabassous centralis (Miller 1899): a new host to Paracoccidioides brasiliensis. Molecular identification of the isolate. Med Mycol 43(3): 275-80, 2005.

COSTA A.A., GOMEZ F.J., PEREIRA M., FELIPE M.S., JESUINO R.S., DEEPE G.S. JR, SOARES C.M. A. Characterization of a gene which encodes a mannosyltransferase homolog of Paracoccidioides brasiliensis. Microbes Infect. 4: 1027-1034, 2002.

COSTA, M., BORGES, C. L., BAILAO, A. M., MEIRELLES, G. V., MENDONCA, Y. A., DANTAS, S. F., DE FARIA, F. P., FELIPE, M. S., MOLINARI-MADLUM, E. E., MENDES-GIANNINI, M. J., FIUZA, R. B., MARTINS, W. S., PEREIRA, M. AND SOARES, C. M. Transcriptome profiling of Paracoccidioides brasiliensis yeast-phase cells recovered from infected mice brings new insights into fungal response upon host interaction. Microbiology 153: 4194-207, 2007.

COUTINHO, Z. F., SILVA, D., LAZERA, M., PETRI, V., OLIVEIRA, R. M., SABROZA, P. C. AND WANKE, B. Paracoccidioidomycosis mortality in Brazil (1980-1995). Cad Saude Publica 18(5): 1441-54, 2002.

FEITOSA LS, CISALPINO PS, SANTOS MR, MORTARA RA, BARROS TF, MORAIS FV. Chromosomal polymorphism, syntenic relationships, and ploidy in the pathogenic fungus Paracoccidioides brasiliensis. Fungal Genet. Biol. 39, 60-69, 2003.

FELIPE, M. S., ANDRADE, R. V., ARRAES, F. B., NICOLA, A. M., MARANHAO, A. Q., et al. Transcriptional profiles of the human pathogenic fungus Paracoccidioides brasiliensis in mycelium and yeast cells. J Biol Chem 280(26): 2470614, 2005.

FONSECA CA, JESUINO RS, FELIPE MS, CUNHA DA, BRITO WA, SOARES CMA. Two-dimensional electrophoresis and characterization of antigens from Paracoccidioides brasiliensis. Microbes. Infect. 3:535-542, 2001.

FRANCO M, BAGAGLI E, SCAPOLIO S, LACAZ C S. A critical analysis of isolation of Paracoccidioides brasiliensis from soil. Med. Mycol. 2000. 38: 185-91, 2000.

FRANCO, M. Host-parasite relationships in paracoccidioidomycosis. J Med Vet Mycol 25(1): 5-18.1987.

JAMES, S. A., COLLINS, M. D. AND ROBERTS, I. N. Use of an rRNA internal transcribed spacer region to distinguish phylogenetically closely related species of the genera Zygosaccharomyces and Torulaspora. Int J Syst Bacteriol 46(1): 189-94, 1996.

JESUÍNO RSA, Efeito da anfotericina B no crescimento, diferenciação e síntese protéica do fungo Paracoccidioides brasiliensis. 1995. 85f. Dissertação (Mestrado em Biologia Celular - Área de Concentração: Ciências Fisiológicas) - Instituto de Ciências Biológicas, Universidade Federal de Goiás, Goiânia, 1995.

LACAZ CS, PORTO E, MARTINS JEC. Paracoccidioidomicose. Micologia Médica. São Paulo. p.248-292, 1991.

LACAZ CS, SAMPAIO SAP. Tratamento da Blastomicose Sul Americana com anfotericina B. Resultados preliminares. Rev Paul Med. 52:443-50, 1958.

LECLERC, M. C., PHILIPPE, H. AND GUEHO, E. Phylogeny of dermatophytes and dimorphic fungi based on large subunit ribosomal RNA sequence comparisons. J Med Vet Mycol 32(5): 331-41, 1994.

LOOSE, D. S., STOVER, E. P., RESTREPO, A., STEVENS, D. A. AND FELDMAN, D. Estradiol binds to a receptor-like cytosol binding protein and initiates a biological response in Paracoccidioides brasiliensis. 
Proc Natl Acad Sci U S A 80(24): 7659-63, 1983.

LÓPEZ-VILLAR E, MONTEOLIVA L, LARSEN MR, SACHON E, SHABAZ M, PARDO M, PLA J, GIL C, ROEPSTORFF P, NOMBELA C. Genetic and proteomic evidences support the localization of yeast enolase in the cell surface. Proteomics 6: 107-18, 2006.

LUTZ, A. Uma micose pseudo-coccídica localizada na boca e observada no Brasil: contribuição ao conhecimento das hiphoblastomicoses americanas. Bras. Med. 22:121-124, 1908.

MARQUES SA, CORTEZ DB, LASTÓRIA JC, CAMARGO RMP, MARQUES MEA. Paracoccidioidomycosis: frequency, morphology, and pathogenesis of tegumentary lesions. An. Bras. Dermatol., Rio de Janeiro, v. 82, n. 5, 2003.

MARTINEZ, R. Blastomicose-SulAmericana (Paracoccidioidomicose) Etioepidemiologia e Ecologia. Tratado de Infectologia. R. Veronesi and R. Focaccia, Ateneu: 1082, 1997.

MATUTE, D. R., SEPULVEDA, V. E., QUESADA, L. M., GOLDMAN, G. H., TAYLOR, J. W., RESTREPO, A. AND MCEWEN, J. G. Microsatellite analysis of three phylogenetic species of Paracoccidioides brasiliensis. J Clin Microbiol 44(6): 2153-7, 2006.

MOREIRA SF, BAILAO AM, BARBOSA MS, JESUINO RS, FELIPE MS, PEREIRA M, SOARES CMA. Monofunctional catalase $\mathrm{P}$ of Paracoccidioides brasiliensis: identification, characterization, molecular cloning and expression analysis. Yeast, v. 30, p. 173-182, 2004.

MURRAY, P. R., G. S. KOBAYASHI, M. A. PFALLER \& K. S. ROSENTHAL.

Microbiologia Médica. Ed. Guanabara

Koogan. Rio de Janeiro, RJ. 2004.
PANIAGO AM, AGUIAR JI, AGUIAR ES, DA CUNHA RV, PEREIRA GR, LONDERO AT, WANKE B. Paracoccidioidomycosis: a clinical and epidemiological study of 422 cases observed in Mato Grosso do Sul. Rev Soc Bras Med Trop. 36:455-459, 2003.

PANUNTO-CASTELO A, FREITAS-DASILVA G, BRAGHETO IC, MARTINEZ R, ROQUE-BARREIRA MC. Paracoccidioides brasiliensis exoantigens: recognition by IgG from patients with different clinical forms of paracoccidioidomycosis. Microbes infect 5: 1205-1211, 2003.

PEREIRA LA, PEREIRA M, FELIPE MS, ZANCOPE-OLIVEIRA RM, SOARES CM. 2004. Proteomic identification, nucleotide sequence, heterologous expression and immunological reactivity of the triosephosphate isomerase of Paracoccidioides brasiliensis. Microbes Infect. 6(10):892-900.

QUEIRÓS-TELLES F. Treatment of patients with paracoccidioidomycosis: new insights and approaches. ARBS. Ann Rev BioSci. Special Issue. 26-7, 2002.

QUEIROZ-TELLES, F. Paracoccidioides brasiliensis ultrastructural Wndings.

Paracoccidioidomycosis. M. Franco, C. S. Lacaz, A. Restrepo-Moreno and G. Del Negro. London, CRC Press: 27-44, 1994.

RAPPLEYE, C. A. AND GOLDMAN, W. E. Defining virulence genes in the dimorphic fungi. Annu Rev Microbiol 60: 281-303, 2006.

RESTREPO A \& JIMÉNEZ B. E. Growth of Paracoccidioides brasiliensis yeast phase in a chemically defined medium. J. Clin.

Microbiol. 12, 279-281, 1980.

RESTREPO, A. The ecology of

Paracoccidioides brasiliensis: a puzzle still unsolved. Sabouraudia 23(5): 323-34, 1985.

RESTREPO, A., MCEWEN, J. G. AND CASTANEDA, E. The habitat of

Paracoccidioides brasiliensis: how far from 
solving the riddle? Med Mycol 39(3): 233-41, 2001.

RESTREPO-MORENO, A.

Paracoccidioidomycosis. Clinical Mycology. W. E. Dismukes, P. G. Pappas and J. Sobel. New York, Oxford University Press: 328345, 2003.

RICHINI-PEREIRA, V. B., BOSCO, S. D., GRIESE, J., THEODORO, R. C., MACORIS, S. A., DA SILVA, R. J., BARROZO, L., TAVARES, P. M., ZANCOPE-OLIVEIRA, R. M. AND BAGAGLI, E. Molecular detection of Paracoccidioides brasiliensis in road-killed wild animals. Med Mycol: 1-6, 2007.

SALEM-IZAAC, S.M.; GÓMEZ, J.; JESUÍNO, R.S.A.; FONSECA, C.A.; PEREIRA, M.; FELIPE, M.S.S.; DEEPE, G.S.J.; SOARES, C.M.A. Molecular Cloning, Characterization and Expression of a Gene Encoding the Heat Shock Protein 60 from Paracoccidioides brasiliensis. Med. Mycol., v.39, p.445-455, 2001.

SAN-BLAS G, NIÑO-VEGA G.

Morphogenesis in Other Agents of Systemic Mycoses in: Pathogenic Fungi: Structural Biology and Taxonomy. Calderone R.A., Cihlar A.R .R.L . 2004.

SAN-BLAS, G. Paracoccidioidomycosis and its etiologic agent Paracoccidioides brasiliensis. J Med Vet Mycol 31(2): 99-113, (1993).

SAN-BLAS, G. AND NINO-VEGA, G. Paracoccidioides brasiliensis: virulence and host response. Fungal pathogenesis: principles and clinical applications. $\mathrm{R}$. $\mathrm{L}$. Cihlar and R. A. Calderone. New York, Marcel Dekker: 205-242, 2001.

SAN-BLAS, G., NINO-VEGA, G. \& ITURRIAGA, T. Paracoccidioides brasiliensis and paracoccidioidomycosis: molecular approaches to morphogenesis, diagnosis, epidemiology, taxonomy and genetics. Med Mycol 40(3): 225-42, 2002.
SAN-BLAS, G., SAN-BLAS, F., RODRIGUEZ, L. E. \& CASTRO, C. J. A model of dimorphism in pathogenic fungi: Paracoccidioides brasiliensis. Acta Cient Venez 38(2): 202-11, 1987.

SANO, A., NISHIMURA, K. \& MIYAJI, M. The Research Encouragement Award. Effects of sex hormones on sexual difference of experimental paracoccidioidomycosis.

Nippon Ishinkin Gakkai Zasshi 40(1): 1-8, 1999.

SCHAECHTER, M., N. C. ENGLEBERG, B. J. EISENSTEIN \& G. MEDOFF. (2002).

Microbiologia: Mecanismos das Doenças Infecciosas. Ed. Guanabara Koogan. Rio de Janeiro, RJ. 642 pgs.

SHIKANAI-YASUDA MP, TELLES FILHO FQ, MENDES RP, COLOMBO AL, MORETTI ML. Consenso em paracoccidioidomicose. Rev Soc Bras Med Trop. 39:297-30, 2006.

SVIDZINSKI, T. I., MIRANDA NETO, M. H., SANTANA, R. G., FISCHMAN, O. \& COLOMBO, A. L. Paracoccidioides brasilienses isolates obtained from patients with acute and chronic disease exhibit morphological differences after animal passage. Rev Inst Med Trop Sao Paulo 41(5): 279-83, 1999.

TERÇARIOLI G, BAGAGLI E, REIS G, THEODORO R, BOSCO S, MACORIS S, RICHINI-PEREIRA V. Ecological study of Paracoccidioides brasiliensis in soil: growth ability, conidia production and molecular detection. BMC Microbiology. 7(1): 92, 2007.

THEODORO, R. C., CANDEIAS, J. M., ARAUJO, J. P., JR., BOSCO SDE, M., MACORIS, S. A., PADULA, L. O., FRANCO, M. \& BAGAGLI, E. Molecular detection of Paracoccidioides brasiliensis in soil. Med Mycol 43(8): 725-9, 2005.

VALERA, E. T., MORI, B. M., ENGEL, E. E., COSTA, I. S., BRANDAO, D. F., 
NOGUEIRA-BARBOSA, M. H., QUEIROZ, R. G., SILVEIRA, V. D., SCRIDELI, C. A. AND TONE, L. G. Fungal infection by Paracoccidioides brasiliensis mimicking bone tumor. Pediatr Blood Cancer, 2008.

VILLA, L. A., TOBON, A., RESTREPO, A., CALLE, D., ROSERO, D. S. \& GOMEZ, B. L. Central nervous system paracoccidioidomycosis. Report of a case successfully treated with itraconazol. Rev Inst Med Trop São Paulo 42(4): 231-4, 2000 .

VILLAR, L. A., SALAZAR, M. E. \& RESTREPO, A. Morphological study of a variant of Paracoccidioides brasiliensis that exists in the yeast form at room temperature. J Med Vet Mycol 26(5): 269-76, 1998. 